\title{
LA APLICACIÓN DE INTERESES EN EL PROCESO LABORAL
}

\author{
POR CONSUELO FERREYRA ${ }^{1}$
}

Sumario: I. Introducción. II. La obligación de resarcir como obligación de dar suma de dinero en el régimen del CCCN. III. Los intereses como vía de actualización "indirecta". IV. Tasa de interés aplicable. V. Facultad judicial para determinar intereses y potestad para declarar la inconstitucionalidad de la ley. VI. Conclusiones.

\section{I.- Introducción}

En un contexto de economía inestable e inflacionaria, el debate acerca de la actualización judicial de créditos provenientes de indemnizaciones recobra especial trascendencia y enciende nuevamente el alcance entre la tesis nominalista y valorista y la aún vigente prohibición de actualización monetaria o repotenciación de deudas cualquier sea su causa.

Si bien el debate no es nuevo, si no por el contrario, el tema de la actualización monetaria mediante la aplicación de intereses ha sido objeto de innumerables discusiones doctrinarias y jurisprudenciales. Se pretende hacer un repaso para analizar su aplicación judicial actual en el ámbito laboral.

El tema en cuestión merece análisis sobre los siguientes puntos a saber: el encuadramiento de las indemnizaciones principalmente como obligaciones de dar sumas de dinero, la determinación de la deuda, su necesidad de actualización y los intereses como vía indirecta de reajuste.

A partir de dicha revisión conceptual es que se analiza cuál ha sido la tasa judicial aplicable por los tribunales, cuestionamiento que deriva la necesidad de analizar el origen de la facultad judicial para determinar intereses y su consiguiente potestad para declarar la inconstitucionalidad de las leyes.

\section{La obligación de resarcir como obligación de dar suma de dinero y el régimen del CCCN}

Las obligaciones de dar sumas de dinero se encuentran reguladas actualmente en el art.765 CCCN, categoría que a su vez distingue entre: i) Obligaciones dinerarias: referido a aquéllas en las que el dinero está determinado o es determinable desde el inicio de la obligación y en donde rige el principio nominalista, con la consiguiente prohibición de las cláusulas de estabilización; ii) Obligaciones de valor: que son aquéllas en las que la deuda consiste en un cierto valor, que es transformado en dinero en un momento posterior al del nacimiento de la obligación (art.772); y por último las iii) Obligaciones en moneda extranjera: que no tienen carácter dinerario y, por lo tanto, si la obligación se pacta en moneda extranjera, es considerada como dar cantidades de cosas (art.765). ${ }^{2}$

Frente a todo crédito el deudor de una obligación deberá responder por la suma con-

1 *Abogada(UNC), Máster en Derecho Empresario(Universidad Austral), docente de DTySS de la UBP, USigloXXI y UNC, publicista. 2 LORENZETTI, Ricardo Luis (dir), Código Civil y Comercial Comentado, Rubinzal Culzoni - $1^{\text {a }}$ ed. ,Santa Fe, 2014, p. $121 .$. 
traída con más sus accesorios a fin de que el acreedor obtenga una adecuada reparación. Ante ello, números pronunciamientos tanto de doctrina como jurisprudencia han intentado delimitar si la obligación de indemnizar se refiere a un valor abstracto o a una suma de dinero. Esta distinción cobra especial trascendencia frente a la prohibición establecida en la ley de convertibilidad $N^{\circ} 23.928$, sancionada en el año 1991, que en su art. $7^{\circ}$ consagró el sistema nominalista al prohibir todo tipo de actualización monetaria, indexación por precios, variación de costos o repotenciación de deudas. Dicha prohibición se mantuvo en la etapa de emergencia económica (2002-2015 inclusive) mediante la ley N²5.561 que conservó en materia de actualización de deudas, la misma redacción que la Ley de Convertibilidad y que continúa vigente en la actualidad.

Este cuerpo normativo se complementó con el art.276 de la LCT, norma que debe considerarse formalmente derogada desde 1991 por la prohibición de actualización monetaria mencionada, que preveía el ajuste cuando resulten afectados por la depreciación monetaria, conforme la variación que experimente el índice de los precios al consumidor en la Capital Federal, desde la fecha en que debieron haberse abonado hasta el momento del efectivo pago. ${ }^{3}$

La regla nominalista despeja, en principio, el campo de discusión entre obligaciones dinerarias y de valor, aunque hay quienes entienden que dicha prohibición solo rige respecto de las obligaciones dinerarias quedando excluidas las de valor como pueden ser las de reparar siniestros laborales al igual que la de resarcir daños y perjuicios. ${ }^{4}$

Podrían excluirse incluso las prestaciones laborales en general por su carácter alimentario que supone la posibilidad de ajustar las remuneraciones de los trabajadores a través de la negociación colectiva y en relación a las obligaciones judiciales la necesidad de recomponer los créditos ante los vaivenes monetarios. ${ }^{5}$

Nos enfrentamos entonces a un panorama en el que se contraponen por un lado una prohibición legal y por el otro, una realidad económica cambiante en el que los constantes fenómenos inflacionarios alejan la brecha existente entre el crédito originario y su quantum a valor real al momento de su determinación, y por tanto la necesidad de actualización de los mismos a los fines de asegurar al damnificado la reparación integral a que tiene derecho.

\section{Los intereses como vía de actualización indirecta}

En primer lugar corresponde conceptualizar a los intereses como "aumentos que las deudas pecuniarias devengan en forma paulatina, durante un tiempo dado, sea como precio por el uso de un dinero ajeno o como indemnización por un retardo en el cumplimiento de una obligación dineraria. Se trata de las rentas, frutos, utilidades o beneficios que producen una suma de dinero, que no brotan en un momento dado si no que germinan y se acumulan continuamente a través del tiempo". ${ }^{6}$

\footnotetext{
3 Artículo sustituido por art.1 de la Ley $\mathrm{N}^{\circ} 23.616$ (B.O., 10/11/1988).

4 Distinción que resalta Marcelo Cagna sobre autores como Moisset de Espanés y Lorenzetti, que establecieron al comentar las modificaciones del art. 722 CCCN que la obligación de valor permanece al margen del nominalismo (CANGA, Marcelo. "El dogma nominalista y la reparación "sistémica" de los siniestros laborales como obligación de valor". Revista de Derecho Laboral-Actualidad, 2019- 1-, Rubinzal Culzoni, Santa Fe, p. 135).

5 GILETTA, Ricardo. "Los intereses en el proceso laboral”. Revista Catorce Bis. Año VII- No 26 Junio/Julio/Agosto 2013, Asociación Argentina de Derecho del Trabajo y de la Seguridad Social, Córdoba, p.5.

6 BUSSO, Eduardo, Código Civil anotado, Ediar, Buenos Aires, 1985- T. IV, p. 266.
} 
De dicho concepto se puede extraer la clásica distinción entre intereses compensatorios como aquellos se deben por tener el capital ajeno o que debe entregarse a otra persona en concepto de precio; y los moratorios como aquellos que se deben por haber ingresado al deudor en estado moratorio, los cuales se dividen a su vez en moratorios propiamente dichos (art. $768 \mathrm{CCCN}$ ) y punitorios como sanción por cumplimiento oportuno de la obligación. (art. $769 \mathrm{CCCN}$ ).

Resulta de interés su distinción conforme su fuente, ya que mientras que los ítems resarcitorios se deben por causa del daño derivado del hecho lesivo primario, la obligación de pago de intereses moratorios responde a otro hecho dañoso distinto que es el no cumplimiento oportuno de la obligación. ${ }^{8}$

Corresponde asimismo distinguir el concepto de intereses del de "actualización monetaria", que aunque la pérdida del poder adquisitivo es parte del interés se considera que jurídicamente se trata de rubros ontológicamente diversos.

La CSJN tiene dicho que la actualización monetaria no aumenta la deuda, si no que la limita a recomponer en los valores de la prestación debida. Esto es integra la "cuenta" del capital adeudado, y no la "cuenta" de los intereses.

Sin embargo, pese a la distinción efectuada, en el marco de un sistema nominalista como el nuestro al estar vedada la actualización por "vía directa", se recurre a la actualización por "vía indirecta" incorporando de algún modo en los intereses un componente inflacionario, que desfigura el rol de los mismos y que en nada se asemeja al origen o fuente de los intereses compensatorios o moratorios.

Resulta en los hechos la forma a la que se recurre para actualizar las deudas pese a la prohibición legal, más aún en el ámbito laboral en donde el trabajador, sujeto de especial protección constitucional, se encuentre afectado frente a la depreciación irrazonable de su crédito frente a una realidad económica en la que la inflación no amaga a disminuir.

\section{IV) Tasa de interés aplicable}

Resulta importante diferenciar las clases de intereses ya referida de la "tasa de interés" que puede ser definida como el rendimiento de la unidad de capital en una determinada unidad de tiempo.

En cuanto al tipo de tasa, al no existir normativa aplicable en la materia que determine de manera uniforme que tasa judicial aplicar, la misma ha ido variando según las circunstancias del momento, y los tribunales han fluctuado en su aplicación a fin de compensar al trabajador por el deterioro de su crédito a través del tiempo.

En su mérito, ante un panorama de economía inestable los tribunales buscaron diversas alternativas para compensar el deterioro del signo monetario mediante la aplicación de un interés puro o complejo mediante la utilización de índices correctores o

\footnotetext{
7 Código Civil y Comercial de la Nación Comentado, dirigido por Ricardo Luis Lorenzetti, 1ª ed., Rubinzal Culzoni, Santa Fe, 2014, p. 137.. 8 ZAVALA DE GONZALEZ, Matilde- MORENO, Graciela Melania, Los intereses en la responsabilidad civil, JA- 1985-IV-713. 9 CCNN Comentado, ob. cit., p. 137.
} 
tasas financieras (activa y pasiva)..$^{10}$

En general la tasa pasiva es la que el banco paga a sus depositantes y la tasa activa es la que la entidad financiera cobra a sus clientes por el dinero prestado. Ésta es más elevada al estar compuesta por varios conceptos como ser el costo que abona la entidad bancaria al depositante que colocó el dinero en el banco (tasa pasiva), gasto de mantenimiento de cartera, previsión por riesgos de cobrabilidad, gestión de cobranza por mora, carga fiscal, costo por encaje bancario, costo de infraestructura técnica y humana del banco, tasa real o pura de ganancia del banco."1

En cuanto a la aplicación judicial durante el periodo de convertibilidad (19912002), los tribunales recurrieron a la tasa fija de interés puro del 12\% anual. Tras el dictado del decreto 941/91 que propiciaba la aplicación de la tasa pasiva bancaria, comenzó un giro hacia las tasas financieras. El 3/3/92 la CSJN se pronuncio por mayoría en el leading case "YPF c/ Provincia de Corrientes y otro" imponiendo la aplicación de tasa activa publicada mensualmente por el BCRA" con la finalidad de mantener incólumne el contenido económico de la prestación a partir de la convertibilidad, criterio luego reiterado en "López c/Explotación Pesquera de la Patagonia”12 (Sent. del 10/6/92, JA 1992-II-10).

Durante el periodo de post convertibilidad, la CSJN mantuvo su criterio en torno a la tasa activa. El 22 de marzo del 2002 se emite el primer pronunciamiento que declara inconstitucional la prohibición indexatoria de la ley 23.928 en la causa "Rodríguez Pedro c/ Carlos Meana y otro" e impuso accesoriamente una tasa de interés puro del $12 \%$ anual.

El 25/6/2002 en los autos "Hernández Juan Carlos c/ Matricería Austral” el TSJ de la Provincia de Córdoba decidió aplicar a partir del 7/02/2002 la tasa pasiva promedio del BCRA incrementada en un 2\% mensual, resaltando el carácter provisorio de la decisión y sujetando la misma a revisiones según las circunstancias futuras.

La CSJN por su parte el 8/11/2016 en autos "Puente Oliera, Mariano c/ Tizado Patagonia Bienes Raíces del Sur SRL s/ despido"’3 revocó la sentencia dictada por la Cámara Nacional de Apelaciones del Trabajo, Sala III, que condenó al empleador a abonar al trabajador una suma de dinero en concepto de comisiones por venta, determinando la aplicación de la tasa de interés activa del Banco de la Nación Argentina y su actualización monetaria. Con este pronunciamiento, reiteró el criterio contrario a la indexación o actualización monetaria, especificando en el dictamen emitido por el Procurador que la aplicación de cláusulas de actualización monetaria significa traicionar el objetivo antiinflacionario que se proponen alcanzar las leyes federales mencionadas (leyes 23.928 y 25.561). ${ }^{14}$

\footnotetext{
10 El interés puro nada tiene que ver con la depreciación del signo monetario por cuanto parte de un capital incólume en periodos de estabilidad económica o previamente corregido por actualización de su monto. El interés complejo en cambio, comprende además del interés puro otras variables que hacen al costo dinerario fundamentalmente la tasa de inflación. (GILETTA, ob.cit.,p. 8).

11 HIGHTON, Elena. "Intereses y puntos de partida” en Obligaciones dinerarias e intereses. Tomo 2- Año 2001, Rubinzal Culzoni, Santa Fe, p.96.

12 GILETTA, ob.cit.,p.9.

13 CSJN, 8/11/2016, "Recurso de hecho deducido por la demandada en la causa "Puente Oliera, Mariano c/ Tizado Patagonia Bienes Raíces del Sur SRL s/ despido"..

14Ver http://sjconsulta.csjn.gov.ar/sjconsulta/documentos/ver documento.html?idAnalisis=734410\&interno=1.
} 
En Córdoba, el 22/10/2018, el TSJ reiteró el criterio adoptado en "Hernández" en "Fernández Danie/ Marcelo c/Virglinio Alberto Alejandro"”s, en donde se adiciono un interés de tasa activa nominal equivalente a la que cobra el Banco de la Provincia de Córdoba para préstamos personales a personas físicas en el plazo de cuarenta y ocho meses y ordeno modificar el interés dispuesto y establecer la tasa pasiva promedio nominal mensual del BCRA con más el dos por ciento mensual, conforme jurisprudencia desde "Hernández", debiendo aplicarse la tasa pasiva del BCRA con más el dos por ciento (2\%) mensual hasta la fecha del efectivo pago de los créditos. ${ }^{16}$

Si bien los más altos tribunales ya han definido su criterio sobre la tasa a aplicar y la vigencia en la prohibición de actualización monetaria, se siguen dando tanto a nivel nacional como provincial cuestionamientos judiciales en torno a la las tasas aplicables (en Córdoba específicamente la tasa "Hernández") por considerar que las mismas no alcanzan a cubrir el crédito frente al proceso inflacionario.

Dichos cuestionamientos ha dado lugar a que los jueces es su carácter de operadores jurídicos analicen si resulta procedente declarar la inconstitucionalidad de la prohibición de actualizar los créditos laborales a pedido de parte (o incluso de oficio) con el argumento de que mediando inflación, tal normativa provoca una merma confiscatoria del capital de carácter alimentario.

A modo de ejemplo merece resaltar pronunciamientos recientes de la Cámara Única del Trabajo, Córdoba, Sala Primera'7, del vocal Ricardo A. Giletta.

Explica el Vocal que no toma como referencia índice INDEC en el periodo anterior a diciembre de 2016 por haber sido objeto de innumerables embates y cuestionamientos y haberse iniciado una nueva etapa a partir de esta fecha por resultar sus indicadores, coincidente con el denominado 'índice Congreso', las mediciones del Observatorio Social citado y las cifras informadas por la Dirección de Estadísticas y Censos de la Provincia

Postula realizar un exhaustivo análisis en cada caso concreto y cotejar el resultante de la aplicación de la tasa "Hernández" con los valores actuales de las obligaciones admitidas, e incluso realizar un análisis comparativo con el marco salarial actual y al advertir que esa vía de ajuste no preserva de manera suficiente el quantum del crédito en su valor real, actualiza los mismos con una tasa diferenciada.

Es estos casos las obligaciones admitidas se actualizan hasta diciembre del 2016 mediante coeficiente RIPTE publicado por el Ministerio de Trabajo, Empleo y Seguridad Social de la Nación, y desde diciembre 2016 en adelante mediante índice INDEC. AI resultado que arroja el incremento porcentual de uno sobre el otro se le aplica asimismo un internes del $15 \%$ anual.

El decisorio se fundamentó principalmente en la afectación de garantías cons-

15 Fernández Daniel Marcelo c/ Virglinio Alberto Alejandro- Recurso de Casación. Expte Nº 300700”,sentencia N ${ }^{\circ}$ 181,22/10/2018.

16 Sostuvo el TSJ de Córdoba que "Si bien la determinación de la tasa respectiva es materia reservada a los jueces de la causa, en el caso el defecto constatado justifica su tratamiento. Ello por cuanto esta Sala no puede desentenderse de la función unificadora a su cargo, debiendo primar el principio de igualdad de los ciudadanos ante la ley".

17 Autos: "Torres, Nuria Fernanda c/ AUKAMAN S.A. -Ordinario - Despido", "Pastore, Romina Paola C/ GUÍA LABORAL Empresa de Servicios Eventuales S.R.L. - Ordinario - Despido", "Maldonado, Marian Soledad c/ Abrate Sergio José y otro - Ordinario- Despido",entre otros. 
titucionales que implican los arts.7ํ y 10 de la ley 23.928, el derecho de propiedad garantizado por el art.17 CN, el art.16 CN que garantiza la igualdad ante la ley, ya que la prohibición de actualización monetaria otorga un claro privilegio al deudor, que por el paso del tiempo y su propia mora terminaría cancelando sus deudas y una desigualdad considerable con otros trabajadores acreedores que en casos idénticos sean indemnizados con prontitud, ya que no sufrirían los efectos depreciatorios de la inflación.

\section{Facultad judicial para determinar intereses moratorios. Potestad de la Cámara para pronunciarse sobre la constitucionalidad de la ley}

Específicamente en cuanto a los intereses moratorios previstos en el art. 768 del CCCN, se establece que la tasa se determinará: a) por lo que acuerden las partes; b) por lo que dispongan las leyes especiales; c) en subsidio, por tasas que se fijen según las reglamentaciones del Banco Central.

Dicha distinción se refiere a la clasificación según su origen que podrá convencionales cuando es fijado por las partes en un contrato o convención o legal cuando reconocen su fuente en la ley.

En la redacción anterior del Código Civil estaban regulados en el art.622 sobre la base del principio por el cual en caso de mora en cumplir una obligación el deudor siempre debía pagar intereses, a diferencia de los compensatorios que no se debían si no estaban pactados. Asimismo, los primeros se debían conforme a la tasa fijada por las partes, por la ley o en su ausencia a los que fijara el juez.

Cabe resaltar entonces, que ya no se defiere a los jueces fijar la tasa moratoria si no que se sustituye por las reglamentaciones del Banco Central de la Republica Argentina.

Sin embargo, en cuanto a la factibilidad contenida en el inc.b) que la tasa aplicable sea dispuesta por las leyes especiales, se considera que debe ser entendida en un sentido amplio: no solo por los Poderes Legislativos nacionales y provinciales, los que se encuentran facultados para fijar la tasa aplicable en términos generales, sino que, en caso de omisión, podrá hacerlo el Poder Judicial mediante el mecanismo de los fallos plenarios o la jurisprudencia vinculante..$^{18}$

Con relación al inc. c) donde se autoriza, en subsidio, la determinación de la tasa conforme sea fijada por las reglamentaciones del Banco Central, es subsidiaria por lo tanto sólo será aplicable en caso que no haya acuerdo de partes o disposición legislativa. Asimismo se deja un espacio vacío mientras no dicte esta institución la reglamentación específica. Atendiendo a ello, en las XXV Jornadas Nacionales de Derecho Civil llevadas a cabo en Bahía Blanca - 2015, la Comisión nro. 2 de Obligaciones, estudió y se expidió sobre los intereses moratorios y llegó a las siguientes conclusiones: 1. La previsión del art.768 inc. c) no implica la delegación al Banco Central de la fijación de la tasa, sino que siempre será el juez el que la determinará. Las tasas fijadas por las reglamentaciones del Banco Central servirán como pauta que podrá ser utilizada por el juez en esta tarea (Mayoría). 2. La previsión del art.768 inc. c) implica la delegación al Banco Central de la fijación de la tasa (Minoría). 3. Es necesario que al determinar la tasa

18 FERREIRA RUBIO, Delia M. - ALFERILLO, Pascual E., "Algunas reflexiones sobre los fallos plenarios", en Estudio de Derecho Civil, Libro Homenaje a Luis Moisset de Espanés, Ed. Universidad, Buenos Aires, 1980, p. 585. 
de interés moratoria se fije aquella que aliente el cumplimiento en tiempo propio por el deudor (unánime).

Por último, con respecto a la potestad judicial para pronunciarse sobre la constitucionalidad de la ley, la CSJN en "Puente Oliera, Mariano c/ Tizado Patagonia Bienes Raíces del Sur SRL" ${ }^{\prime \prime}$ en su remisión al dictamen fiscal estableció que "la prohibición de toda clase de actualización monetaria escapa al control de constitucionalidad, pues la conveniencia del criterio elegido por el legislador no está sujeta a revisión judicial (conf. Fallos : 290:245; 306:1964;323:2409; 324:3345;325:2600;327:5614;328:2567:329:385 y 4032 y 330:3109, entre muchos otros ), y la Corte Suprema ha sostenido que los art.7ํ y 10 de la ley 23.928 constituyen una decisión clara y terminante del Congreso Nacional de ejercer las funciones que le encomienda el art.67, inc 10 (hoy art. 75 inc.11), de la Constitución Nacional de "Hacer sellar moneda, fijar su valor y el de las extrajeras...' (conf. Causa "YPF en fallos: 315:158, criterio reiterado en causas 315:992 y 1209; 319:3241 y 328:2567)" (considerando 13)."

La decisión de invalidar una norma comporta la última ratio del orden jurídico, a la que sólo cabe acudir cuando no existe otro medio de salvaguardar algún derecho o garantía amparado por la CN, si no es a costa de remover el obstáculo que representan normas de inferior jerarquía. ${ }^{20}$ En el caso mencionado la Corte consideró que no se acreditó una afectación al derecho de propiedad del actor de tal magnitud que sustente la declaración de inconstitucionalidad de las normas cuestionadas, más aun con la tasa de interés aplicada.

Sin embargo, ello no restringe la posibilidad de analizar en cada caso concreto el eventual perjuicio causado ya que también la Corte ha convalidado la posibilidad de declaración oficiosa de inconstitucionalidad. ${ }^{21}$

\section{CONCLUSIONES}

- La obligación de indemnizar se refiere principalmente a una obligación dineraria, pudiendo excluirse las de reparar siniestros laborales por tratarse obligaciones de valor, las que de todas formas merecen tratamiento diferenciado por haber establecido la ley 27.348 una nueva regla en materia de intereses y de ajustes dinerarios.

- La regla nominalista despeja, en principio, el campo de discusión entre obligaciones dinerarias y de valor, aunque dicha distinción eminentemente teórica carece de sentido si consideramos que la prohibición de actualización es sorteada en la práctica por medio de la actualización por vía indirecta, sin considerar el origen de la misma.

- El concepto de intereses difiere ontológicamente del de "actualización monetaria", que no aumenta la deuda ni contempla el uso del capital ajeno ni la mora en el pago sino simplemente se limita a recompone los valores de la prestación debida.

- La CSJN como el TSJ de Córdoba ya han definido su criterio sobre la tasa a aplicar y la vigencia en la prohibición de actualización monetaria.

- Frente a la prohibición de indexación y ante los cuestionamientos por la limitación de

19 FERREIRA RUBIO, Delia M. - ALFERILLO, Pascual E., "Algunas reflexiones sobre los fallos plenarios", en Estudio de Derecho Civil, Libro Homenaje a Luis Moisset de Espanés, Ed. Universidad, Buenos Aires, 1980, p. 585.

20 Dictamen del 31/5/2007, causa SCC 732, L. XLI "Checmarev, Alejandro c/ YPF SA s/ indemnización enfermedad accidente”.

21 CSJN, "Banco Comercial Finanzas S.A. -en liquidación Banco Central de la República Argentina- s/ quiebra", sent. del 19/8/2004, se sostuvo que "es elemental en nuestra organización constitucional, la atribución que tienen y el deber en que se hallan los tribunales de justicia, de examinar las leyes en los casos concretos que se traen a su decisión, comparándolas con el texto de la Constitución para averiguar si guardan o no conformidad con ésta, y abstenerse de aplicarlas, si las encuentran en oposición con ella". 
las tasas aplicables a cubrir la totalidad del crédito, los pronunciamientos judiciales ha versado entre: i) Declarar la inconstitucionalidad de la ley (ya sea a pedido de parte o de oficio), lo que permite realizar una actualización monetaria, y una vez actualizada la deuda aplicar un interés puro. ii) Mantener la vigencia de la ley e intentar compensar la depreciación monetaria a través de la tasa de interés complejo.

- La declaración de inconstitucionalidad debe ser considerada como última ratio del orden jurídico y requiere inexcusablemente la demostración del agravio en el caso concreto. Asimismo, sólo cabe acudir a tal remedio judicial cuando no existe otro modo de salvaguardar algún derecho o garantía amparada por la Constitución.

- Lo cierto es que a los fines de preservar el quantum del crédito existe como instrumento principal: los intereses, aunque agregar como componente de los mismos la pérdida del poder adquisitivo confunde los conceptos de actualización monetaria e intereses.

- Si aun así ante una causa concreta se ven afectados los derechos constitucionales del actor es potestad de los jueces suplir el derecho cuando el crédito no alcance a ser compensado con aplicación de intereses compensatorios o moratorios.

- En conclusión: como defensa ante el flagelo de la inflación que parece no detenerse, resulta fundamental encontrar los instrumentos necesarios para recompensar de manera adecuada el crédito del trabajador, manteniendo el valor del mismo. Cualquiera sea su forma ya sea mediante tasas de interés puro, complejo o incluso fijando una tasa aplicable uniforme aplicable a todos los créditos laborales, lo importante es evitar que las reglas del mercado vayan por sobre los derechos fundamentales, sobre todo en materia laboral cuando están en juego prestaciones de naturaleza alimentaria. ${ }^{22}$ 